\title{
Increasing economic stability of the industrial enterprise as a result of its market value modeling
}

\author{
M.G. Efimova ${ }^{1, *}$ \\ ${ }^{1}$ South Ural State University, Chelyabinsk, Russia
}

\begin{abstract}
The article deals with an urgent problem of the Russian and global economic stability. The issues of management of the modern industrial enterprise in the conditions of variable economy are considered in this research. Also the article highlights the importance of evaluation of industrial enterprises in Russia nowadays. The management model of the industrial enterprise cost based on sustainability criteria is constructed. The author focuses on new approaches to mathematic modeling of business evaluation. The article contains graphs and charts related to performance of enterprise system and different business strategies based on economic sustainability. Relevant problems of management by means of business assessment for enterprises owners and top managers are defined. The aim of the article is to suggest measures for the Russian industry to manage the cost of enterprises and consequently, to make national economy management more effective.
\end{abstract}

\section{Introduction}

The situation in world economy, developed by 2016 , highlights the existence of strategic, fundamental goal of enterprise development as the most important factor of competitiveness. The growth of market value of the enterprise can become such a purpose in most cases. The Russian and foreign practice shows that the tendency of increasing enterprise cost is the index of stability of functioning and developing the enterprise, and also promotes public welfare increase and improvements in social and economic sphere of the state.

First of all, competitiveness and stability of the enterprise development surely depend on conditions of internal environment of the enterprise. However, the biggest danger is represented by factors of external environment of the enterprise which are not influenced by management and control from the management of the enterprise executives [4, 11].

So, the increase of speed changes in market conditions, and continuous fluctuations of external environment have a rather strong impact on steady performance and development of modern enterprises. It is reflected in crisis phenomena everywhere in economy, frequent geopolitical changes, terrorist threats, sanctions aimed at restriction of opportunities of the Russian economic entities participation in international trade, investment relationships and projects of technological cooperation; fluctuation of exchange rates and energy costs, etc.

For example, economic sanctions imposed on Russia in the context of political crisis development in Ukraine caused a severe damage to positions of the Russian business; and decrease of the world oil prices in the second half of 2015 created significant threats for revenues of the state budget and stability of an exchange rate. As a result, by the end of the year the economy entered the stagnation phase and faced real risks of transition to economic recession at the beginning of 2016.

The enterprises need to provide appropriate and timely responses to disturbing influences of external environment to preserve and strengthen economic and social stability in the state, and also to achieve its global strategic objectives. It will provide both economy in general, and the enterprise in particular with the necessary adaptive potential which being combined with other capacities of the enterprise (such as production, finance, labor, investment, etc.) will guarantee a sustainable development and successful achievement of the demanded results $[3,20]$.

Thus, there is a need to consider external environment and identify the factors which have an impact on the cost of the enterprises to further anticipate, prevent or minimize their negative influence.

\section{Theoretical framework and literature review}

The works of such foreign scientists as G.S. Harrison, J.R. Hicks, K. Walley, G. Teyl, R. Rayleigh, Sh.P. Pratt, R. Link, G.M. Desmond are devoted to theoretical development of the problem of cost and its assessment techniques.

The works of such modern Russian scientists who studied the problems of business evaluation as S.A. Tabakova, L.D. Revutsky, I.I. Kolesnikova, A.G. Gryaznova, M.A. Fedotova, A.M. Sambursky,

Corresponding author: efimovamg@susu.ac.ru 
M.Y. Hodorovsky, E.A. Raush, A.V. Razmakhova, S.A. Kazantseva, V.V. Balakirev, V.V. Grigoriev, A. Volkov, M. Kulikov, V.A. Scherbakov are worth noticing.

The significant contribution to research of issues of a sustainable development and effective management of the industrial enterprise was made by scientists of the Ural economic school of sciences: A.I. Tatarkin, I.A. Bayev, L.A. Bayev, A.V. Schmidt, T.A. Khudyakova, O.A. Nikolayevskaya and others.

Examination and analysis of publications of scholars on the existing problem, and also on experience of economic activity of the industrial enterprises in modern conditions allowed to reveal practical difficulties while implementing a sustainable development strategy which can result in improper business management techniques, including the absence of effective assessment and forecasting model of its cost, taking into account the unavoidable uncertainty of external factors.

The object of the research is the cost of the industrial enterprise in conditions of instability of external environment and methods of management of the industrial enterprise in these conditions.

The goal of the article is to develop the model of the industrial enterprise cost in terms of economic stability in conditions of instability of the external environment based on probabilistic and statistical approach.

\section{Materials and methods}

\section{A. Description of methods}

In modern market environment the evaluation of existing industrial enterprise cost should be a part of its work algorithm and one of tools designed to support the executive staff in management decisions. The enterprise is at growth stage, in other words in economically stable position, if the result of estimation the enterprise market value increased in comparison with the assessment for the previous period. Cost decrease shows a disadvantageous situation in the firm and requires acceptance of immediate measures from the executives [17-19].

The main criterion of economic development of the enterprise as an ability of the enterprise to compete in the market now and in long-term periods is the indicator of market value. [1].

Therefore, for the functioning enterprises it is quite urgent to make an assessment of their market value for prediction of negative impact of environment fluctuations [2].

The management needs to use systematic analysis to develop a technique of industrial enterprise management, taking into account its cost in the conditions of variable economy. It is obviously possible for several reasons which refer to application of systematic approach, namely: the enterprise is an open, goal-based, dynamic system [5].
The conception of the industrial enterprise as a controlled and open system focused on a goal, assumes the possibility to develop an algorithm of managing its financial and economic activity which will allow this system to achieve its strategic objective of functioning and developing in case of possible fluctuations of external and internal environment [9].

Such an algorithm should involve a criterion by which the decision will be further made. In other words, it is necessary to determine the parameter, which can help managers to analyze and carry out management feedback. Therefore, if interrelations between input parameters of the enterprise economic system and a resultant indicator, i.e. cost of the enterprise, are previously known, the process of administrative decision-making will become clear and transparent $[4,5]$.

\section{$B$. The algorithm of seeking ways to enhance efficiency of the administrative system.}

Any executive board needs to create an algorithm of seeking the ways to increase the effectiveness of the administrative system which is based on creation of the industrial enterprise cost model in terms of economic stability. This algorithm can consist of a number of stages. It is rational to accept the following stages as the principal ones:

1) Theoretical research of the system of the industrial enterprise.

This is the stage for goal-setting, identification of needs which will become the basis of administrative actions, determination of an overall strategic objective of the enterprise, identification of tasks to achieve the goal at this stage.

2) Study of general properties of the enterprise system.

To achieve this, it is necessary to set goals and form the model by means of which the influence of external environment factors on a resultant indicator will be studied. 3) Model setting.

The next stage is characterized by development of the model based on probabilistic and statistical approach, as well as quantitative determination of resultant indicator limits in case of a stable position of the system.

4) Model implementation.

Procedures which happen at this stage are listed below: training of the personnel to work with the model, practical application, comparison of results of management with the data of previous periods.

\section{Graphic model}

It can be possible to present a graphic model of the analysis of the industrial enterprise market value on the basis of statistical data. The cost of the enterprise $(\mathrm{Ct})$ should fall within the specified goal interval range from $\mathrm{C} 0$ to $\mathrm{C} 1$, where $\mathrm{C} 0$ and $\mathrm{C} 1$ - respectively the minimum and maximum border of industrial enterprise market value in a stable position of the system. Figure 1 shows this. 


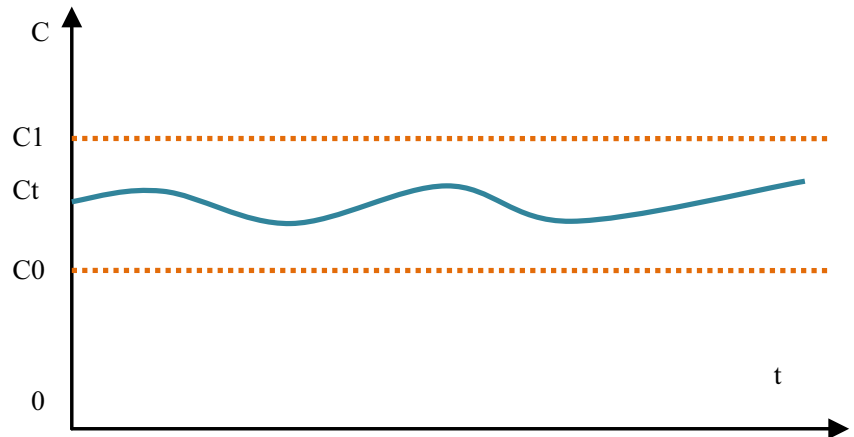

Fig.1. Graphic model of the market value analysis of the industrial enterprise implementing the strategy of stabilization and financial strengthening.

The goal of any enterprise is development and increase of activity efficiency. The graphic model of the analysis of industrial enterprise market value will be quite different at implementation of growth strategy or development. This option can be seen in figure 2 .

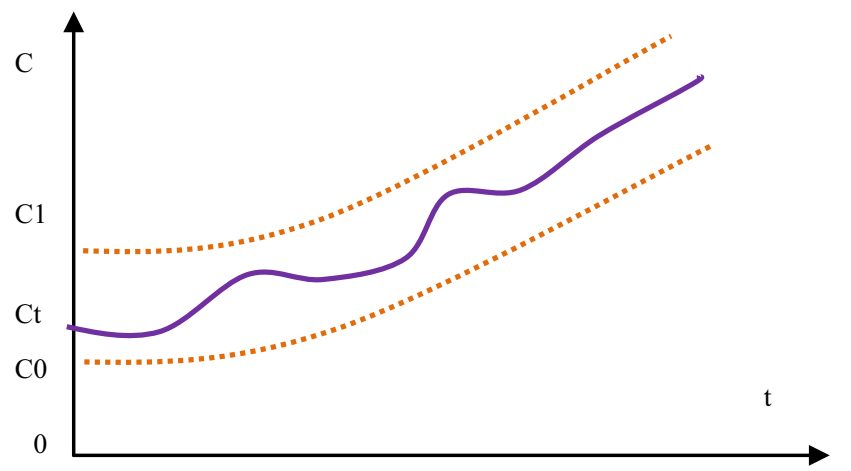

Fig.2. Graphic model of the market value analysis of the industrial enterprise implementing the strategy of growth and development.

Parameters constantly vary depending on disturbing influences of the external and internal environment, and there is a possibility for them to move beyond steady functioning limits.

Therefore, the enterprise needs to develop a system of economic stability control. Also it means to develop tools for integrated management of economic enterprise stability $[8,10,11]$.

It should be noted that there is a need to take into account not only the financial stability of the enterprise, which reflects its liquidity and solvency, but also the economic stability that characterizes the probability of achieving the strategic goals of the company [9].

The model allows to identify the most hazardous impact, which can bring the resulting indicator "market value of the industrial enterprises" out of balance and, consequently, the stability of the whole system out of the zone, as well as to carry out the analysis of the sensitivity of the resulting figure to the disturbing influences of the environment $[6,7]$.

\section{Mathematical economic model}

This method while developing a model, however, cannot provide the executive board and external analysts with the opportunity to confidently describe correlation between the function (an indicator "the market value of the industrial enterprise") and intensity of parameters fluctuations of external and internal environment of the industrial enterprise [12].

Therefore, there is a need to estimate probabilistic dependence of a resultant indicator on fluctuations of parameters which will enter this model.

To solve this problem, it is necessary to divide the entire time interval, which is taken for analysis, into $n \rightarrow+\infty$ number of ranges. In each time point it will be possible to determine the probability of a random variable hit, namely the indicator "market value of the industrial enterprise" in the interval $[\mathrm{CO} ; \mathrm{C} 1]$, which characterizes a zone of a steady condition of system (1) [14-16].

$$
P\left(C 0_{t} \leq \overline{C_{t}} \leq C 1_{t}\right)=\Phi\left(\frac{C 1_{t}-\overline{C_{t}}}{\sigma}\right)-\Phi\left(\frac{C 0_{t}-\overline{C_{t}}}{\sigma}\right),
$$

where $P$ - the probability; $C 0_{t}-$ the minimum border of market value of the enterprise at a steady condition of system; $C 1_{t}-$ the maximum border of market value of the enterprise at a steady condition of system; $\overline{C_{t}}-$ random variable of market value of the enterprise in a time point named t; $\Phi$ - Laplace's function; $\sigma$ - standard deviation of a random variable $\mathrm{S}$.

The probabilistic and statistical model is used for the description of uncertainty which needs to be considered at the administrative decision-making [13].

\section{Conclusions}

Summing up, it should be emphasized that changes of market condition are inevitable and can be characterized by various speed and intensity. It also results in shortterm or long-term violations in proportionality of market process; deviations from the main objective of development. And, as the market is inherently prone to spontaneity, very flexible in the development, responsive to the many social and economic impact, moreover, it is very dependent on political and psychological effects, and the like, therefore, its parameters are subject to fluctuations as randomly and constantly manifested (cyclical and seasonal).

Therefore, under condition of instability of environment factors, the relevance and practical importance of the development of the economic and mathematical model of enterprise value, which will determine the probability of deviation of actual results from planned ones in terms of the system dynamics and possible effects of the environment, significantly increase.

Thus, the criterion which characterizes the model of industrial enterprise market value in terms of the economic stability based on probabilistic and statistical approach is a random variable probability of hitting "the 
market value of industrial enterprises" in the area of sustainable functioning of the system [14-16].

In conditions of unsustainable economy in the modern world the main tasks to be solved by senior management of the industrial enterprise are as follows:

- the constant analysis of market situation;

- timely identification of the risks, associated with instability of economy;

- the development of result application methodology of evaluation of the industrial enterprise cost in management;

- timely administrative decision-making on the basis of the evaluation results analysis;

- the choice of optimum measures of management and preventive actions;

- accurate planning, forecasting and obligatory systematic plan revision.

The executive board has to make decisions to change or promote such strategy which allows the industrial enterprise value fall into the desired range of values. It must be done on the basis of modeling made and the analysis of results. According to them the type and a pattern of management are chosen. The actions involving increase of enterprise efficiency and, in turn, increase of its cost, are selected as well.

The work was supported by Act 211 Government of the Russian Federation, contract № 02.A03.21.0011.

\section{References}

1. T. Kouplend, Business value, estimation and management (Olimp-Bussnes, Moscow, 2007)

2. I.A. Baev, V.I.Shiryaev, E.V. Shiryaev, Dynamic theory of the firm (SUSU Publishers, Chelyabinsk, 2001)

3. T.A. Khudyakova, A.V. Shmidt, Proc. of The 26th International Business Information Management Association Conference, 1617-1625 (2015)

4. M.S. Kuvshinov, Economics \& Management Research Journal of Eurasia, 1, 3-24 (2013)

5. T.A. Khudyakova, A.V. Shmidt, Proc. of The 26th International Business Information Management Association Conference, 1626-1634 (2015)
6. T.A. Khudyakova, A.V. Shmidt, Mediterranean Journal of Social Sciences, 6, 4, 274-279 (2015)

7. O.A. Nikolayevskaya, Management of development of the industrial enterprises on the basis of cost approach (Creative economy, Moscow, 2013)

8. A.V. Shmidt, T.A. Khudyakova, Proc. of The 27th International Business Information Management Association Conference (2016)

9. A.V. Shmidt, T.A. Khudyakova, Proc. of The 27th International Business Information Management Association Conference (2016)

10. T.A. Khudyakova, Proc. Innovative development of modern science: collection of articles, 293-295 (2015)

11. T.A. Khudyakova, Actual problems of economics, 12, 444-450 (2012)

12. T.A. Khudyakova, Proc. of the International Congress on Interdisciplinary Behavior and Social Science 2015, 295-297 (2015)

13. T.A. Khudyakova, Proc. of the International Congress on Interdisciplinary Behavior and Social Science 2015, 292-294 (2015)

14. T.A. Khudyakova, A.V. Shmidt, Proc. of The 26th International Business Information Management Association Conference, 1607-1611 (2015)

15. T.A. Khudyakova, A.V. Shmidt, Proc. of The 26th International Business Information Management Association Conference, 1612-1616 (2015)

16. S.A. Kushtanok, S.G. Spirina, New technologies, 2, 66-74 (2014)

17. S.G. Spirina, Modeling of internal and external factors of financial stability of economic subjects (Krasnodar, 2013).

18. M.G. Efimova, Proc. Breakthrough economic reforms in the conditions of risk and uncertainty, 53-55 (2015)

19. V.I. Vagizova, Problems of modern economy, 4 (2009)

20. A.A. Nikolaenko, Proc. Science SUSU, 1517-1525 (2015) 